\title{
UNIDADE DE SAÚDE BÁSICA EM CHACRAS DE CORIA, MENDOZA, ARGENTINA.
}

UNIDAD DE BÁSICA DE SALUD EN CHACRAS DE CORIA, MENDOZA, ARGENTINA.

\section{BASIC HEALTH UNITY IN CHACRAS DE CORIA, MENDOZA, ARGENTINA.}

\section{GARCIA, JOAQUÍN}

Estudante de arquitetura, Universidade de Buenos Aires, Faculdade de Arquitetura, Desenho e Urbanismo (FADU, UBA). e-mail: garcia.joaquin93@hotmail.com.ar

\section{COMPAGNONI, ANA MARIA}

Professora, Universidade de Buenos Aires, anacompa@terra.com.ar

\section{INTRODUÇÃO}

Para a matéria eletiva "Introdução ao Desenho Bioambiental" do curso de Arquitetura da Faculdade de Arquitetura, Desenho e Urbanismo da Universidade de Buenos Aires (FADU, UBA), estabeleceu-se como objetivo o projeto de uma Unidade Básica de Saúde de pequena escala para abastecer a população local do lugar e cuja intervenção e desenho devem estar guiados por critérios bioclimáticos, atendendo aos condicionantes climáticos, geográficos e culturais próprios do lugar.

O lote de implantação do projeto se localiza em Chacras de Coria, na Província de Mendonza, na região de Cuyo, Argentina. O programa desenvolvido é um edifício de saúde para assistência programada e emergência, cumprindo a função de unidade de referência, já que conta com serviços ambulatoriais básicos como laboratório, raio-x e ecografia, uma sala de emergência e consultórios de serviços médicos e odontológicos.

Assim, dividiu-se o programa em cinco áreas: área pública, área de atendimento ambulatorial, área de segurança, administração e área de serviços. Quanto ao tratamento dos espaços exteriores, foram projetados considerando estacionamento para 10 veículos, uma doca para veículos de detenção e de transporte público, como também estacionamento para ambulâncias e a correspondente faixa de descarga para os serviços do edifício.

O trabalho foi destacado por menção honrosa pelo júri da XI Bienal de Arquitetura Bioclimática "José Miguel Aroztegui"'.

\section{DESENVOLVIMENTO DA PROPOSTA}

O local

Mendonza é uma Província da Argentina, e se trabalhará pontualmente sobre a localidade conhecida como Chacras de Coria (LAT:3259' S LONG:6852'W ALT:921 mts.) (Imagem 1)

O terreno sobre o qual se projeta a Unidade Básica de Saúde, se encontra localizado entre um parque (faceSul) e uma saída de tráfego de veículos de uma avenida (face Norte) (Imagem 2). 
Imagem 1: Localização.

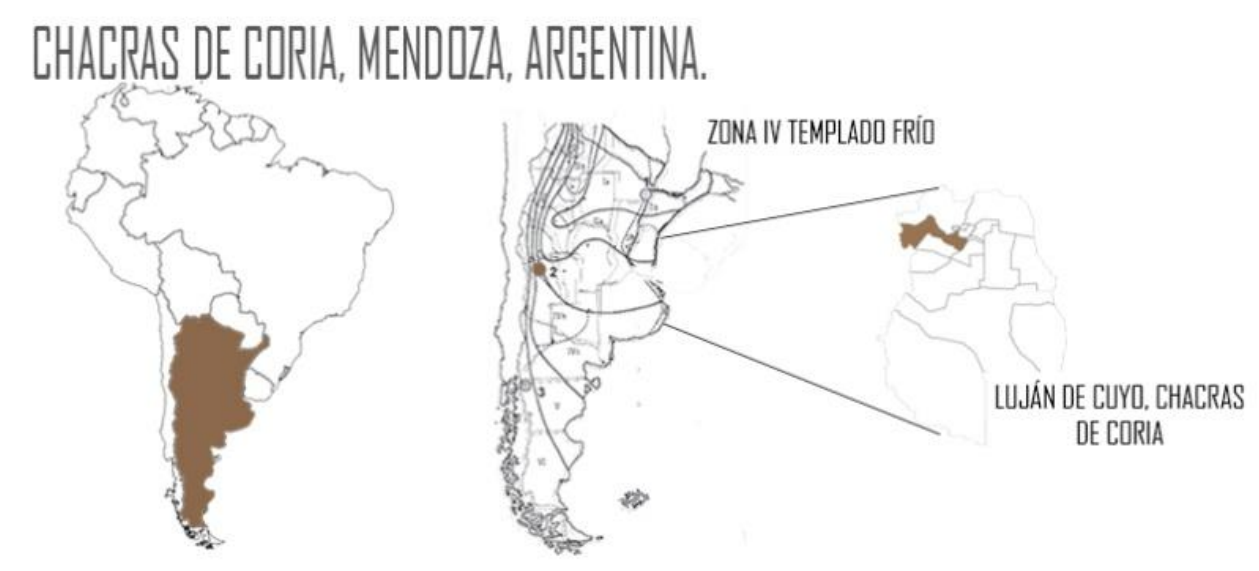

Fonte: Norma IRAM 11603-1996. Zonas Bioambientales

Imagem 2: Terreno de implantação.

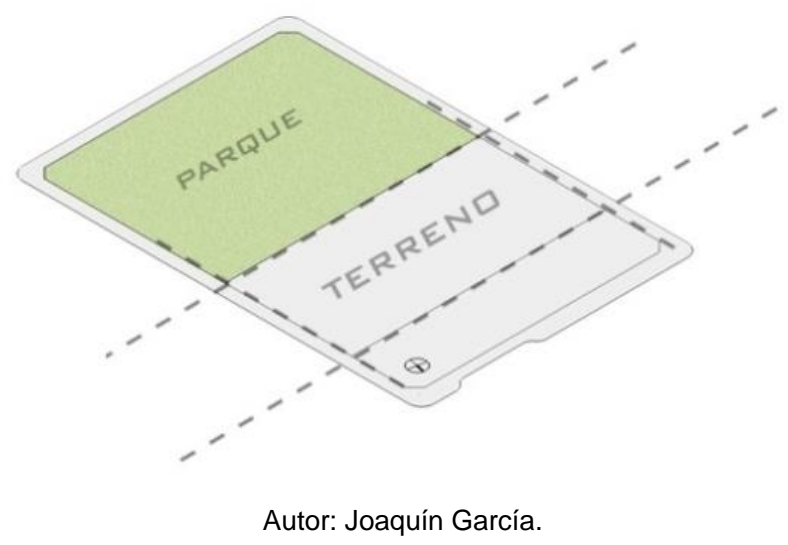

Do estudo das variáveis climáticas do local obtidos de dados metereológicos (Serviço Metereologico Nacional 1992, PEARCE E. A. \& SMITH C. G. 1990), foramregistradas as principais caracteristicas climáticas do lugar (Imagens. 3, 4, 5 ), tais como: grande amplitude térmica anual e diária, característica típica de clima seco, com temperaturas médias no inverno entre $6^{\circ} \mathrm{C}$ e $8^{\circ} \mathrm{C}$ (sendo que as máximas temperaturas nessa época oscilam em valores próximos a $15^{\circ} \mathrm{C}$, e as mínimas próximos a $0^{\circ} \mathrm{C}$ ), e no verão as temperaturas máximas atingem $39^{\circ} \mathrm{C}$, considerando a temperatura de conforto entre os $18^{\circ} \mathrm{C}$ e os $24^{\circ} \mathrm{C}$ ) (Imagem 3 ).

Estudou-se também, a predominância dos ventos e pode-se observar que estes provêm do Sudoeste nos meses de inverno e do Nordeste nos meses de verão, com frequências elevadas mas com velocidades baixas (Imagem 4). 


\section{Imagem 3: Temperatura.}

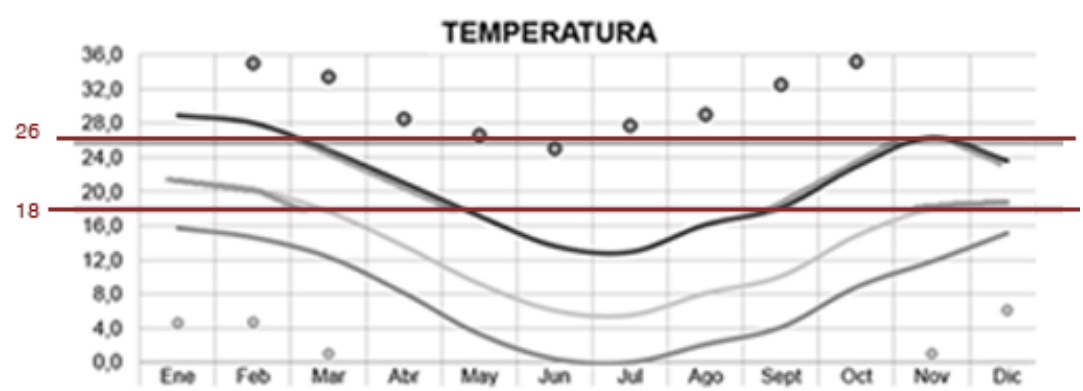

Fonte: CIHE, FADU UBA. Centro de Pesquisa de Habitat e Energia

Imagem 4: Diagramas de Ventos

\section{FRECUENCIA DE VIENTO VELOCIDAD DE VIENTO}
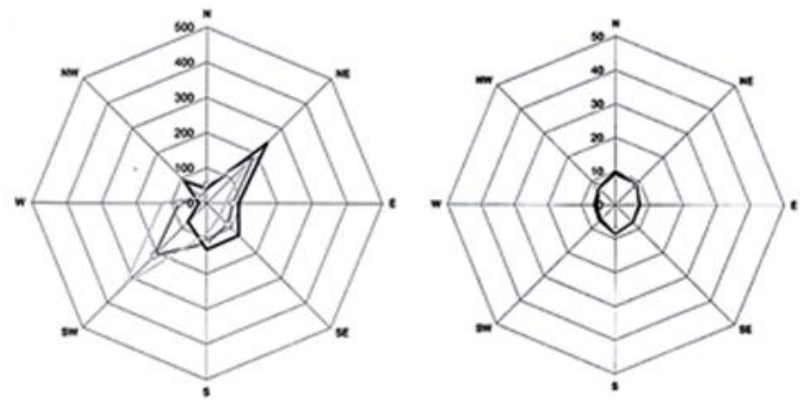

Fonte: CIHE, FADU UBA. Centro de Pesquisa de Habitat e Energia

Também foram analisadas outras variáveis como as condições de céu e nebulosidade e observou-se que, na maior parte do ano, as condições do céu marcam uma maioria de dias semicobertos e a nebulosidade não apresenta grandes variações, com leve aumento nos meses frios (Imagem 5).

Por último, estudou-se a partir do ábaco psicométrico as variáveis e condições climáticas obtidas, para poder estabelecer as estratégias a serem utilizadas no projeto.

Imagem 5: Nebulosidadee Condições do Céu
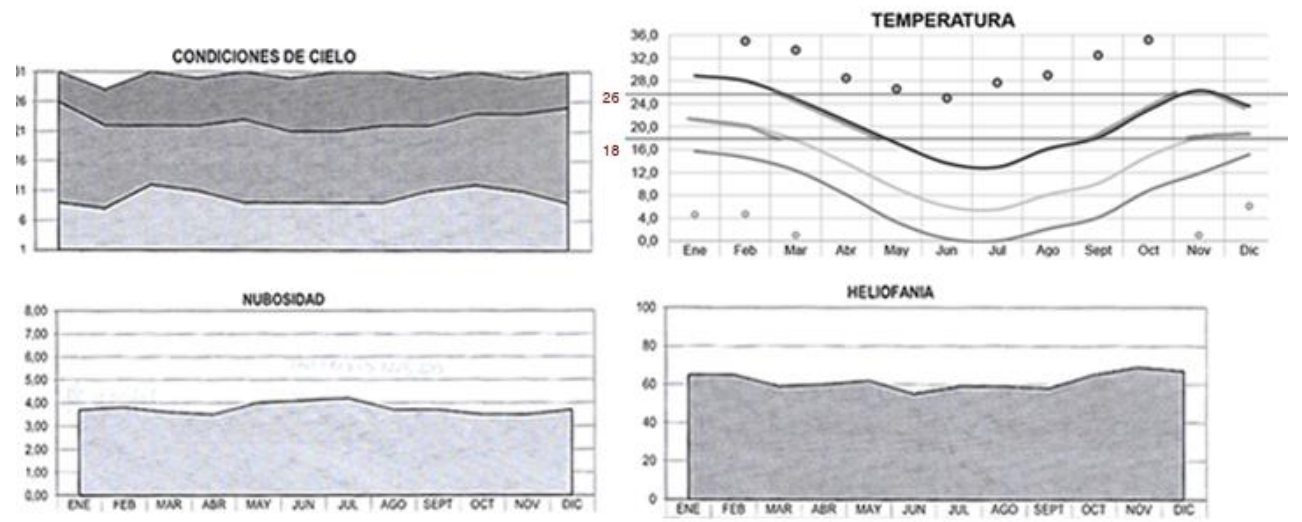

Fonte: CIHE, FADU UBA. Centro de Pesquisa de Habitat e Energia 


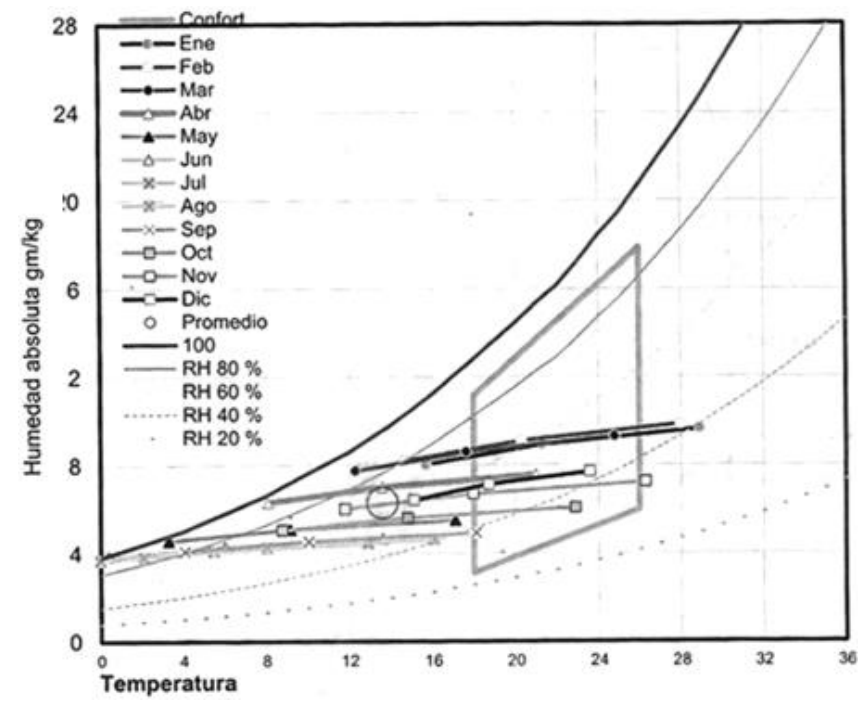

Fonte: CIHE, FADU UBA. Centro de Pesquisa de Habitat e Energia

Vale destacar que o local para o qual se projeta tem as características de Zona Suburbana, cujo microclima é especial, já que mantém uma relação direta com a zona de Cordilheiras (Imagem 7), o qual influencia tanto na vegetação, como também nas características referentes aos ventos predominantes (Vento Zonda), entre outros fatores.

Imagem 7: Chacras de Coria, Luján de Cuyo, Mendoza.
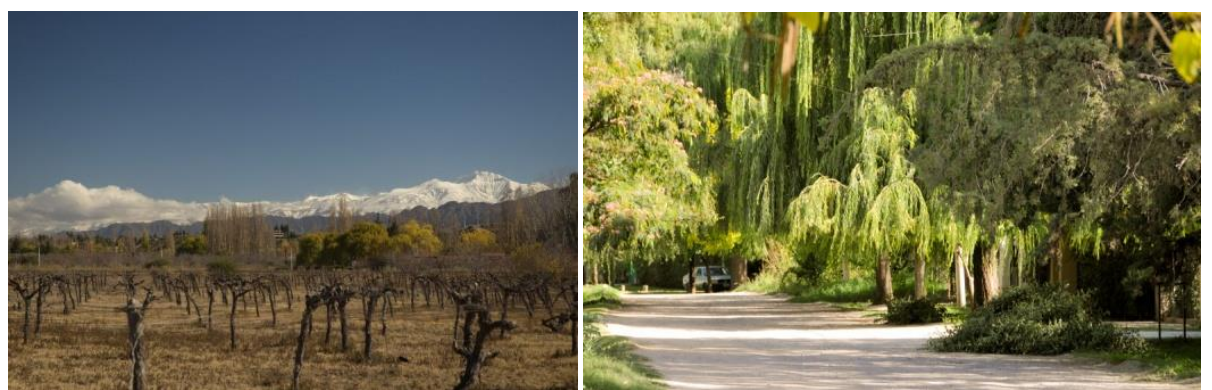

Fonte: www.welcomeargentina.com - www.mendozatravel.com

A partir do estudo dessas variáveis e levando em consideração as condições próprias do programa de necessidades considerado para este centro de saúde, foram determinadas as estratégias bioclimáticas do projeto que foram aplicadas nas diferentes escalas do desenho (EVANS J. M. de SCHILLER S, 1996, OLGAY V., 1998. Y GONZALO G., 2003).

Estas estratégias são as seguintes:

No Inverno: Ganho Solar, Inércia térmica, Isolamento Térmico, Proteção de Ventos.

No verão: Proteção Solar, Inércia térmica, Isolamento Térmico, Ventilação seletiva, Umidificação.

\section{O projeto}

Após a análise climática e geográfica do local, procurou-se alcançar através da morfologia uma forma compacta com um sistema de pátios organizadores de espaços (Imagem 8), que atuam como reguladores microclimáticos do conjunto. Esses pátios estão vinculados através de um eixo organizador que funciona 
como sala de espera e por sua vez atravessa o projeto com maior altura para poder captar o ganho solar nos meses frios desde o Norte.

Por outro lado, tendo em conta as predominâncias dos ventos estudados, buscou-se proteger tanto os espaços abertos (pátios) como fechados, das variações desses fenômenos, através da criação de barreiras de vegetação como primeira instância de proteção (Eixo Sudoeste) e como segunda instância com a mesma morfologia da envoltória do edifício (Imagem 9).

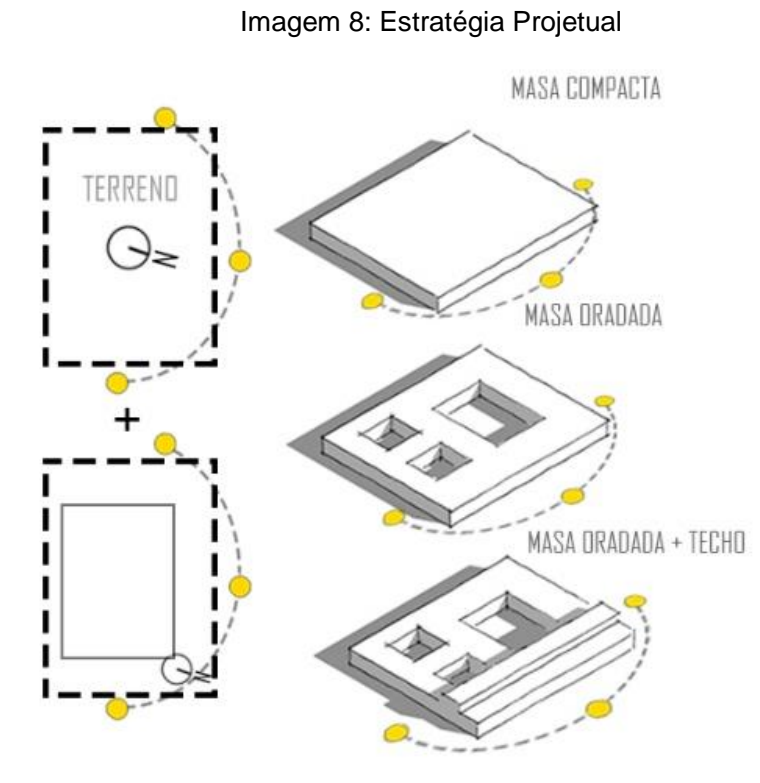

Fonte: autor

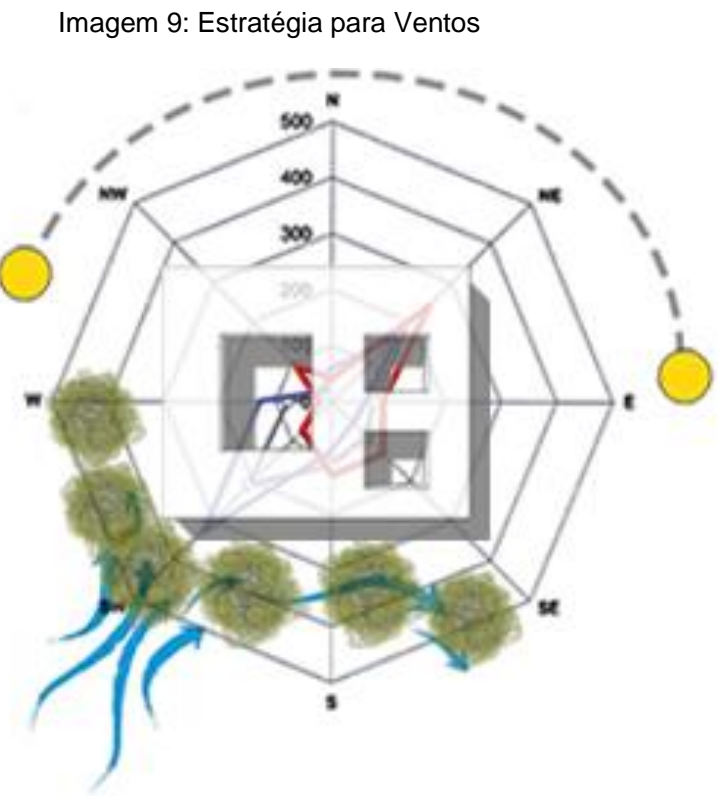

Fonte: autor

Relacionando os usos com as necessidades de condicionamento térmico e as orientações mais favoráveis, foram localizados, em relação a melhor orientação (norte e nordeste), os usos que requeriam maior ganho de captação solar nos meses de inverno, protegendo-os nos meses de verão por meio de beirais. Tanto os consultórios, como os espaços de uso comum e as salas de espera, foram localizados em relação a orientação mencionada (Imagem 10).

Imagem 10: Esquemas de Projeto
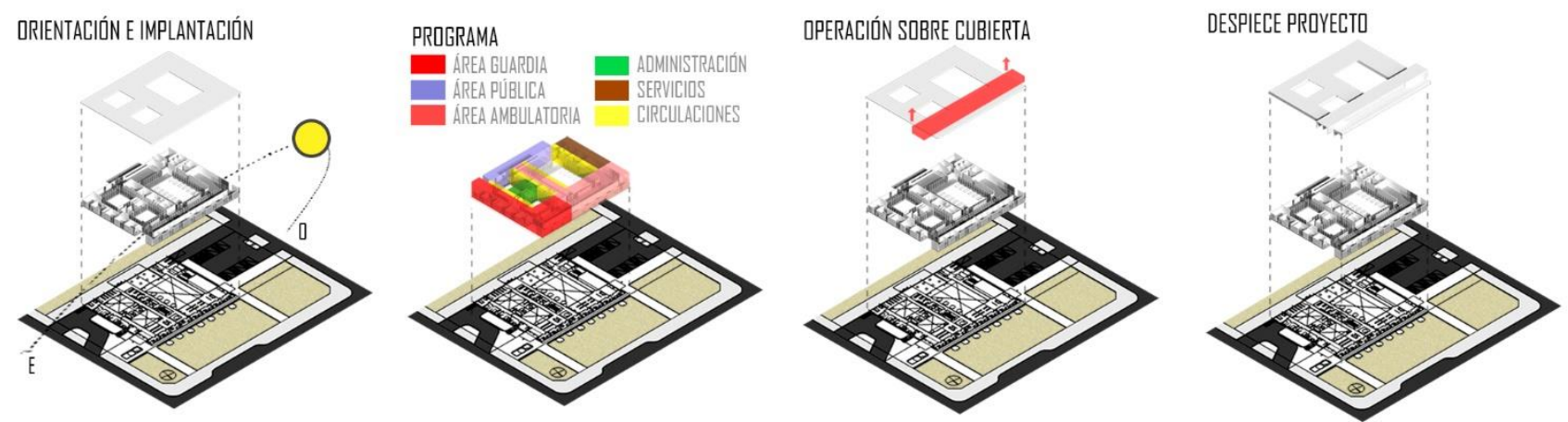

Fonte: autor

O programa de necessidades se distribui em planta em torno dos vazios (pátios), facilitando o controle dos espaços de caráter mais públicos e distribuindo as atividades de caráter privado / técnico/ de apoio (Imagem 11).

As entradas ao edifício se distribuíram em sentido transversal ao mesmo, materializadas com um volume de maior altura, enfatizando assim as salas de espera que se vinculam com os pátios e com os usos que se dispõem segundo a área (área de segurança e área ambulatorial). Por sua vez, o volume de maior altura permite melhor captação solar desses espaços. 
Nas fachadas com boa orientação, começando pela Fachada Norte, se dispõem os usos tais como de consultórios (consultórios gerais, odontológicos e ginecológicos), cuja orientação é a mesma para todos. Vinculados aos pátios, com a mesma orientação (orientação Norte) se localizam usos que não são só de maior utilização, como requerem boas orientações para assegurar condições de conforto, tal como a Administração, o Refeitório, a Sala de Usos Múltiplos.

Entre o Leste/Nordeste se localizam os usos relacionados com a segurança, tais como Laboratórios, Sala de Gesso, Dormitório médico, Sala de observação e Sala de trauma. Todas essas atividades estão vinculadas com o acesso da Sala de Segurança e seus acessos tanto veiculares como de pedestres.

Por outro lado, os usos do programa que não requerem tanto de iluminação natural quanto de boa orientação, são dispostos nas orientações mais desfavoráveis, como é o caso da Sala de Máquinas localizada a Oeste, assim como as Salas de Raio-x, Sanitários e Farmácia.

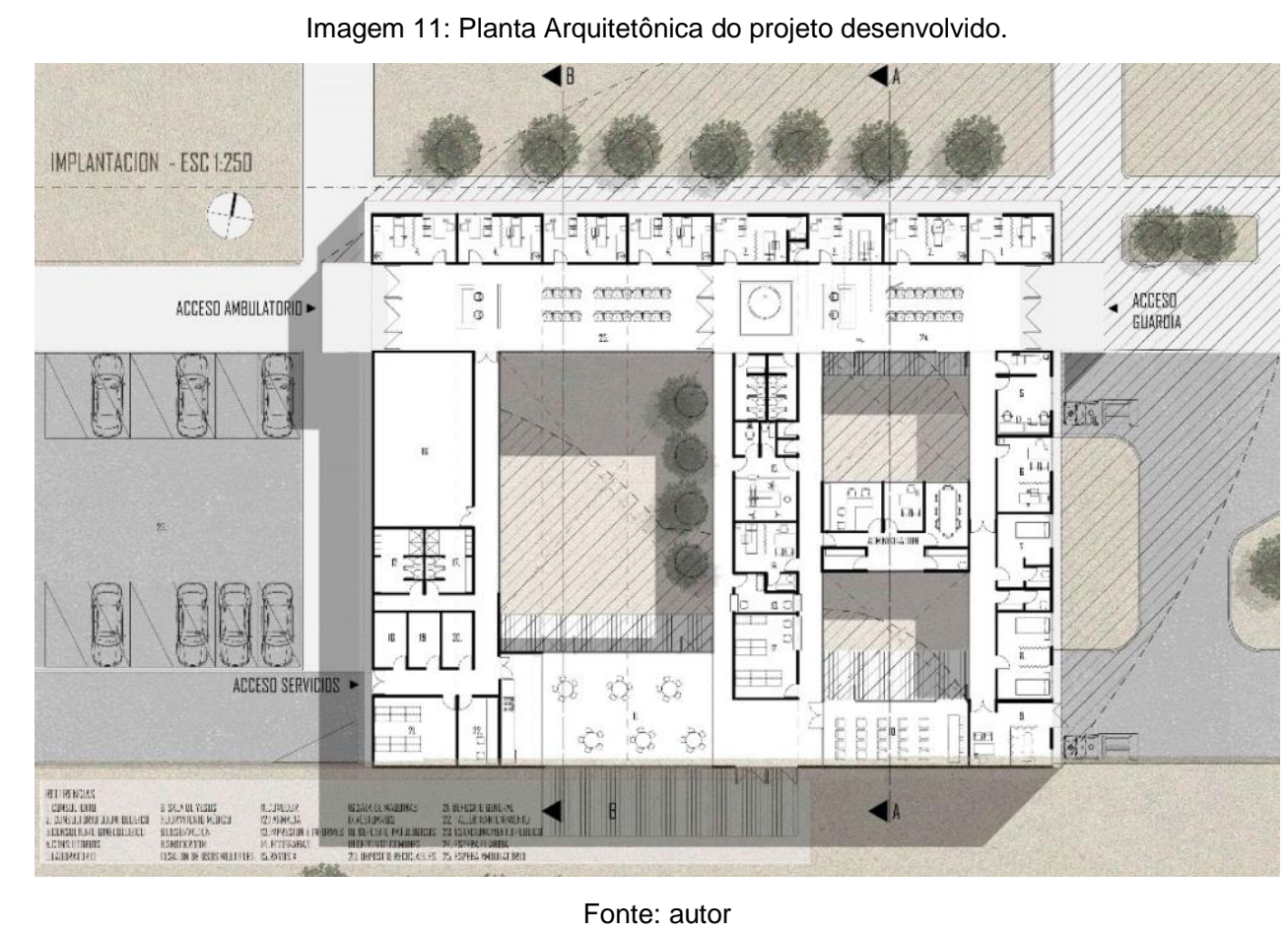

Para reduzir o custo energético para condicionamento térmico dos ambientes principais e contribuir de modo eficiente para o conforto durante os meses de inverno, utilizou-se a estratégia de parede-trombe sobre a fachada Norte como sistema de captação e acumulação de energia solar. A inércia térmica do sistema aproveita grande amplitude térmica do clima para manter as condições mais confortáveis no interior dos ambientes.

Considerando-se que Chacras de Coria tem condições favoráveis durante o dia entre os meses de Setembro e Novembro, para alcançar conforto nos espaços externos, se propõe a disposição árvores de folhas decíduas que proteja do sol no verão e que permita a passagem de raios solares no inverno, favorecendo o uso destes espaços como extensão do interior do edifício. 


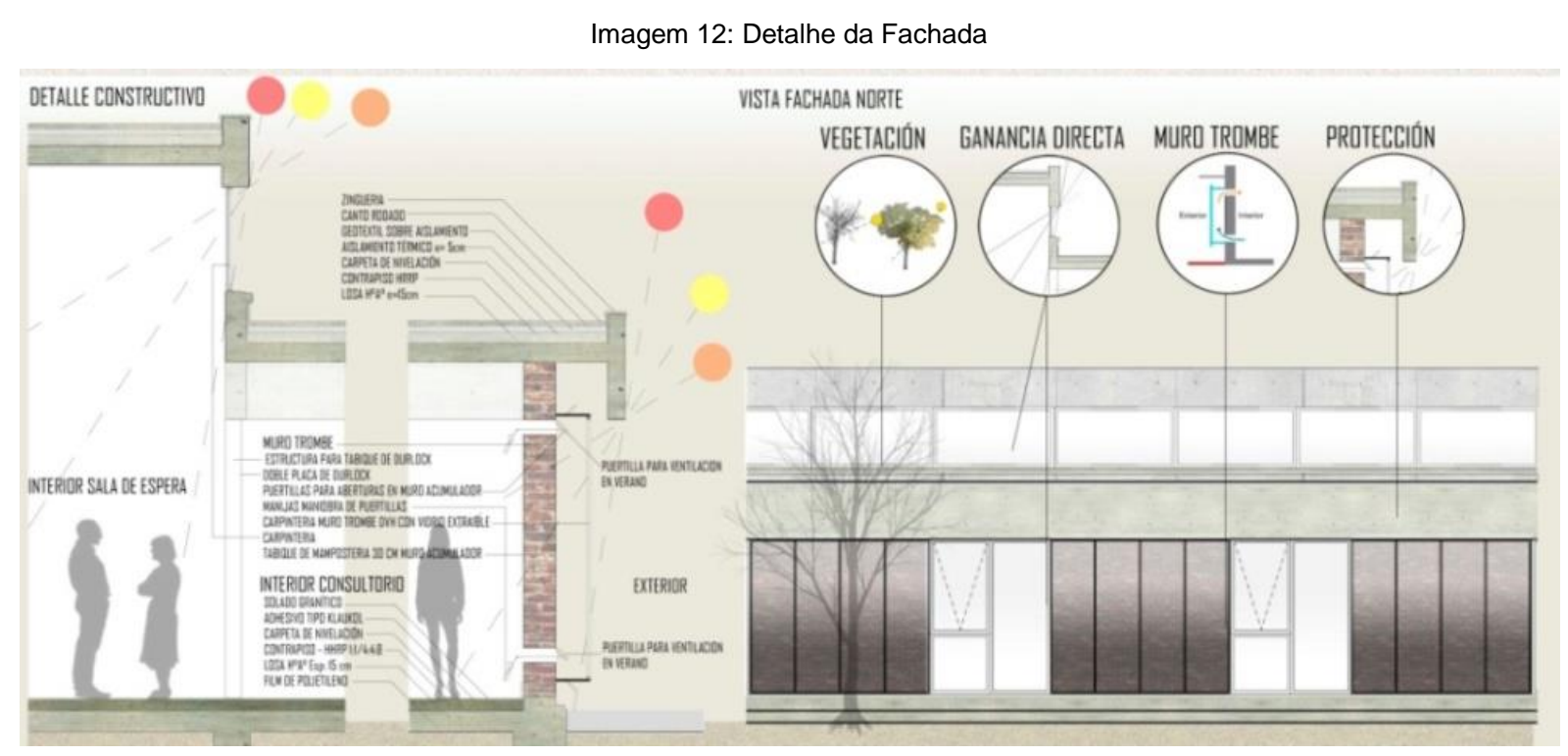

Fonte: autor

Quanto a envoltória do edifício e sua materialidade, o conjunto é conformado por alvenaria de tijolos comuns para os fechamentos, carpintaria DVH e Concreto. Isto foi analisado através de cálculos de balanços térmicos (Imagem 13a e 13b) e calculando os coeficientes de transmissão $\mathrm{K}$ dos materiais, para determinar a espessura, isolamento e requerimento dos diferentes locais a condicionar, a fim de reduzir consideravelmente as perdas no resto das orientações. Isto permitiu dispor de materiais que, com suas respectivas espessuras, funcionassem como elementos de maior inércia. (Imagem 14 e 15).

Imagem 13a: Cálculos do coeficientes de materiais $\mathrm{K}$ na laje de concreto

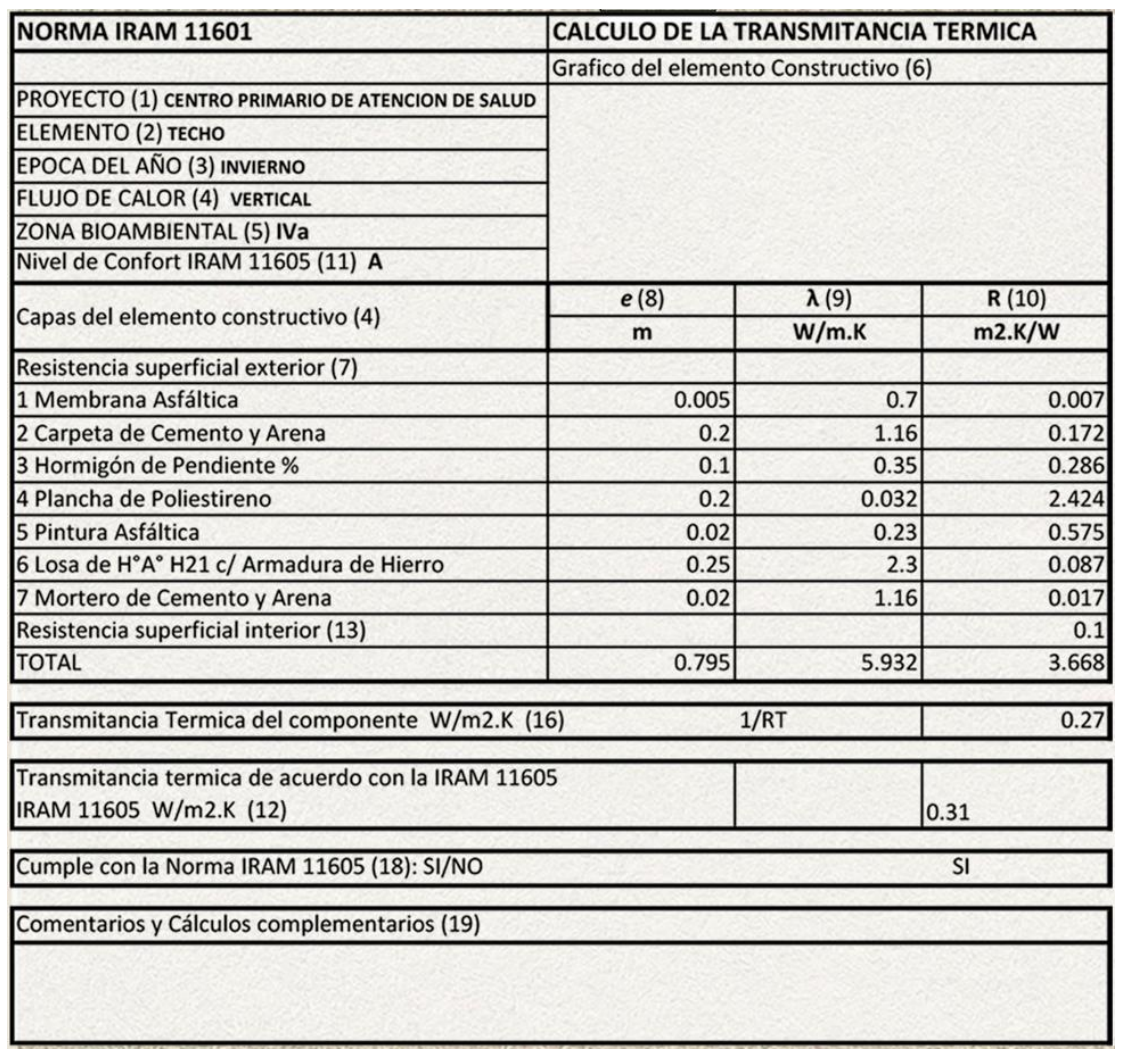

Fonte: autor 
Garcia, J.; Compagnoni, A. M.

Imagem 13b: Cálculos do coeficientes de materiais $\mathrm{K}$ na parede

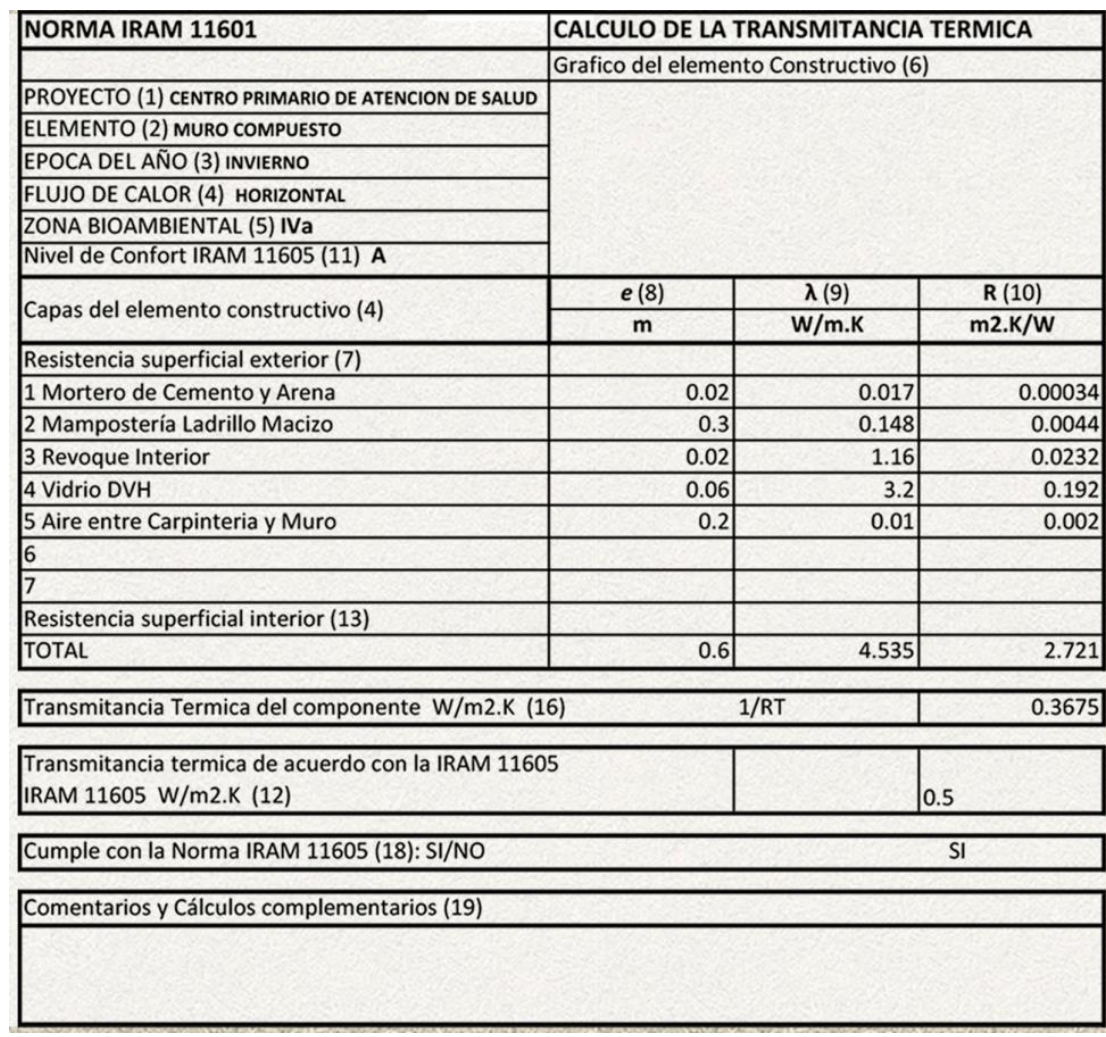

Fonte: autor

Imagem 14: Materialidade do edifício

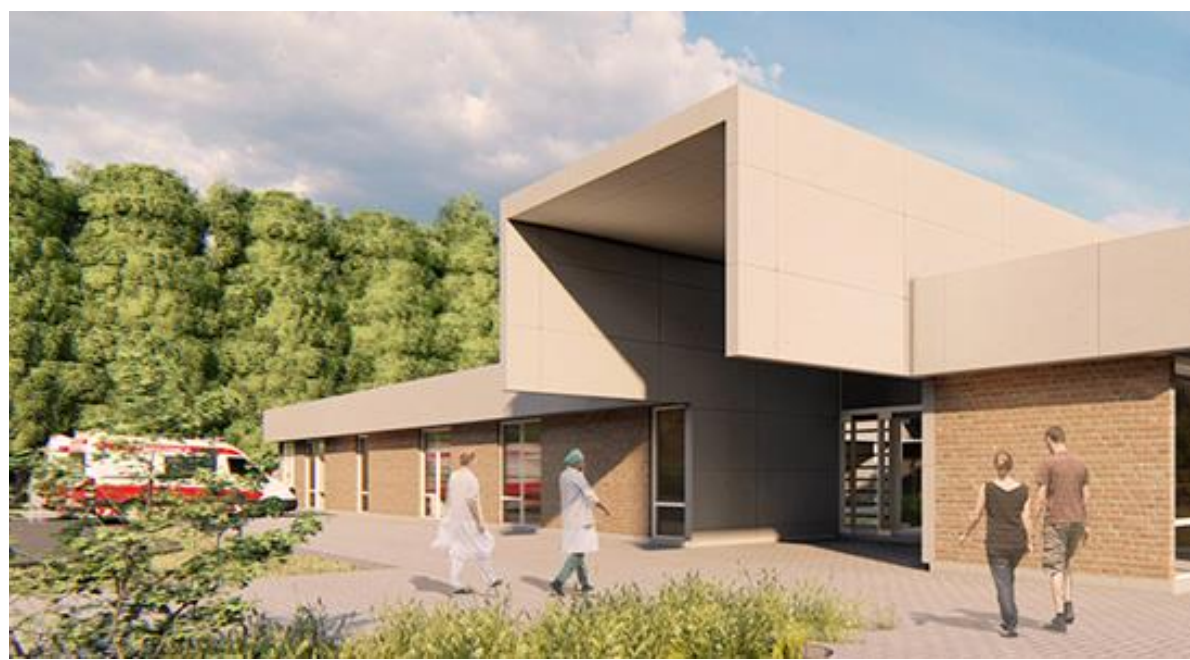

Fonte: autor

Imagem 15: Materialidade do edifício

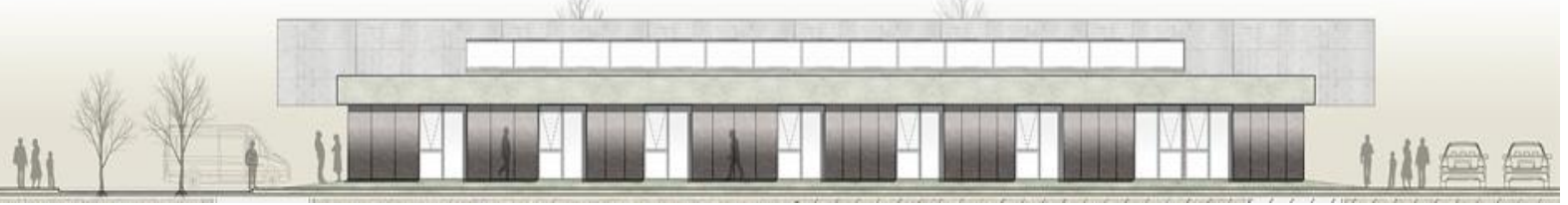

Fonte: autor 


\section{Estudo bioclimático}

Com o objetivo de dar resposta ao requerimento de ganho direto nos meses frios e proteção solar para os meses mais quentes, foram definidas tanto as dimensões dos pátios como a extensão dos beirais e as alturas do edifício, resultando em uma morfologia que contribui de maneira eficiente a estes fatores.

Com os ângulos de incidência solar estudados e analisados, foram determinadas as proteções que cada setor requer, focando-se na intenção de equilibrar os ganhos solares e proteções em cada um deles (Imagem $15 \mathrm{e}$ 16).

Figura 15: Esquemas de Corte

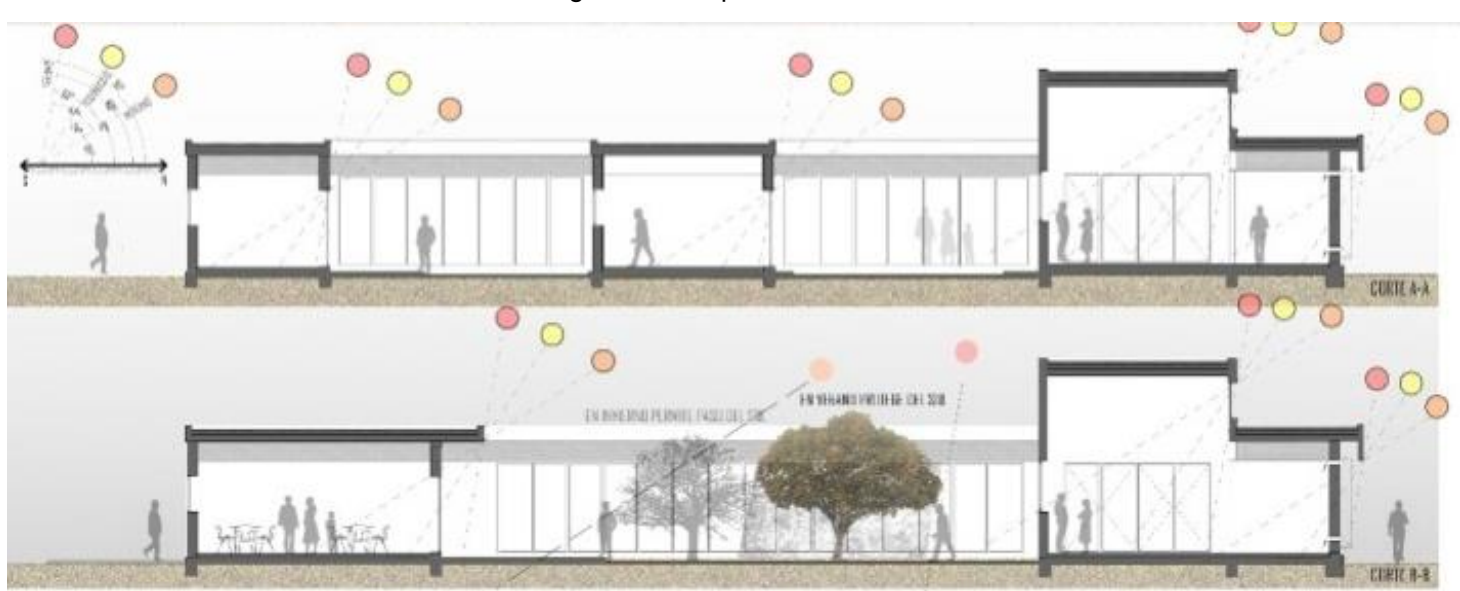

Fonte: autor

Imagem 16: Penetração Solar nas fachadas

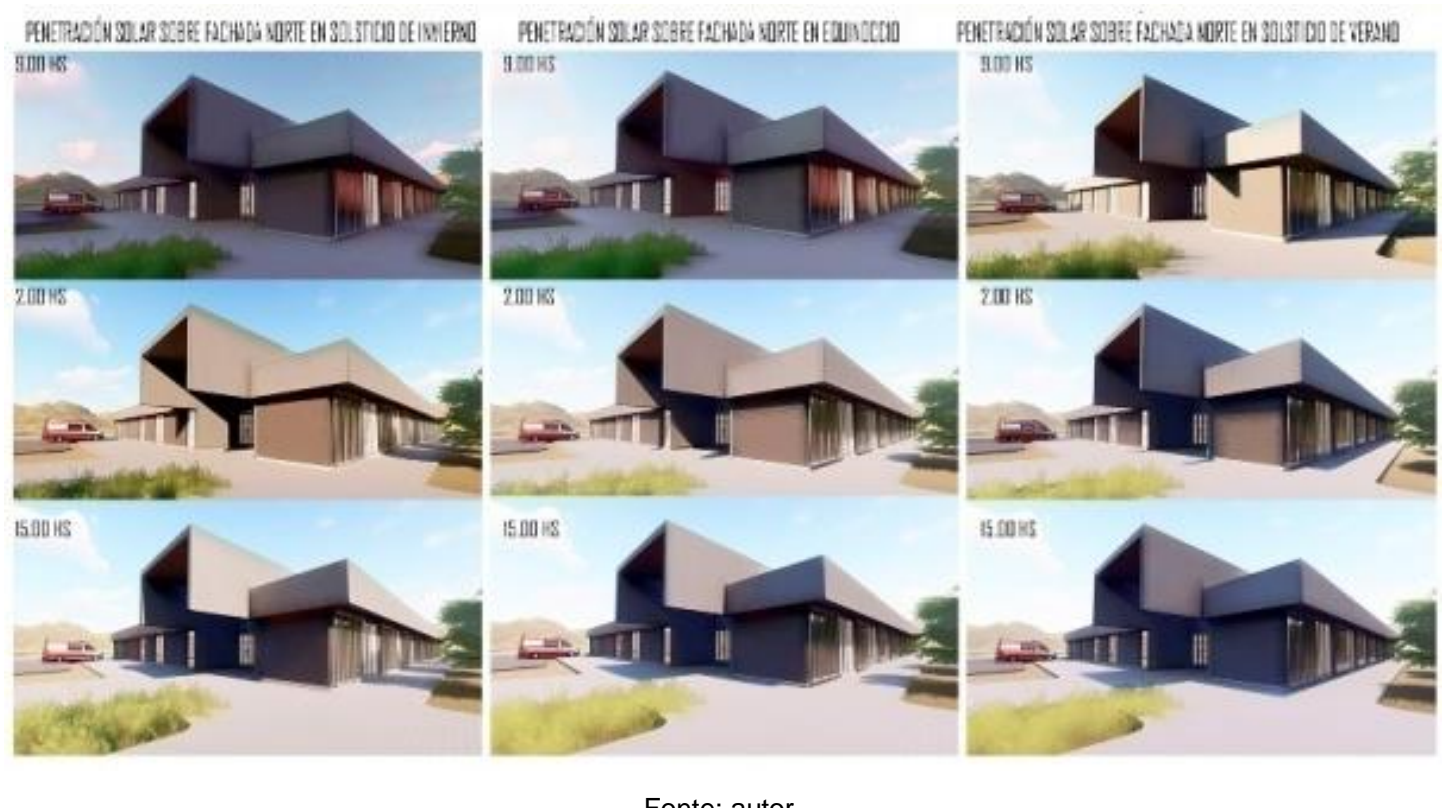

\section{CONSIDERAÇÕES FINAIS}

A Unidade Básica de Saúde projetada busca gerar por meio da compacidade, da simplicidade do volume e seus respectivos vazios, uma relação entre a funcionalidade própria do edifício, que deve responder às necessidades tanto do público como da equipe médica, e a sustentabilidade, onde a prioridade são as boas orientações e o aproveitamento das condições favoráveis de cada época do ano, para assim reduzir o gasto energético por condicionamento. 
É em relação a estes fatores, que a implantação do edifício busca alcançar todas as variáveis estudadas e materializadas através da morfologia, para que na locação do edifício se leve em conta a relação do mesmo com o entorno, não só atendendo ao interesse de conseguir boas orientações, como também obter as vistas que os diferentes usos podem proporcionar. Como é o caso das áreas de uso Público como o Refeitório ou a sala de uso múltiplo, que se vinculam em uma relação direta entre Pátio - Uso - Parque, gerando amplas visualizações que contribui tanto com a qualidade espacial quanto com o aproveitamento do local em relação à sua conexão com o parque do Sul.

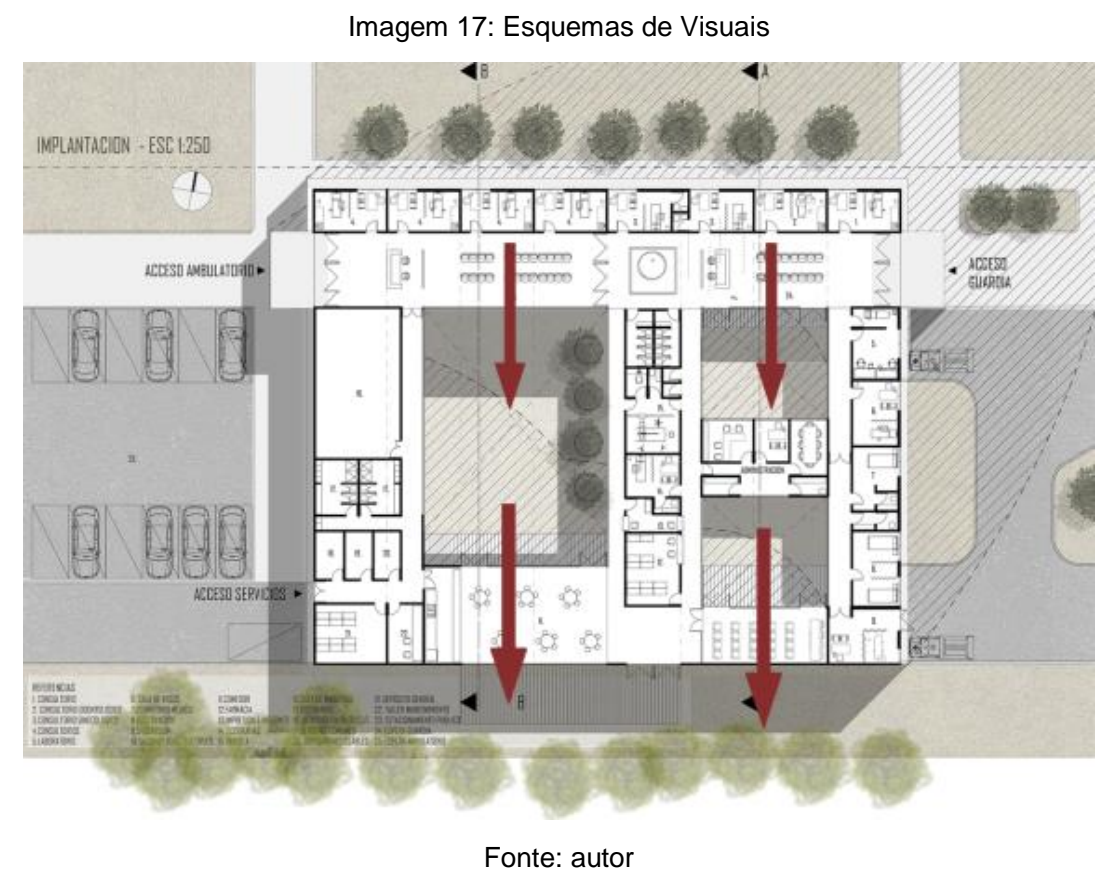

Finalmente, com a união de todos estes parâmetros e junto com a tomada de decisões projetuais do desenho, têm-se a Unidade de Saúde na Província de Mendoza, em Chacras de Coria. (Imagem 18).

Imagem 18: Painel General do Concurso

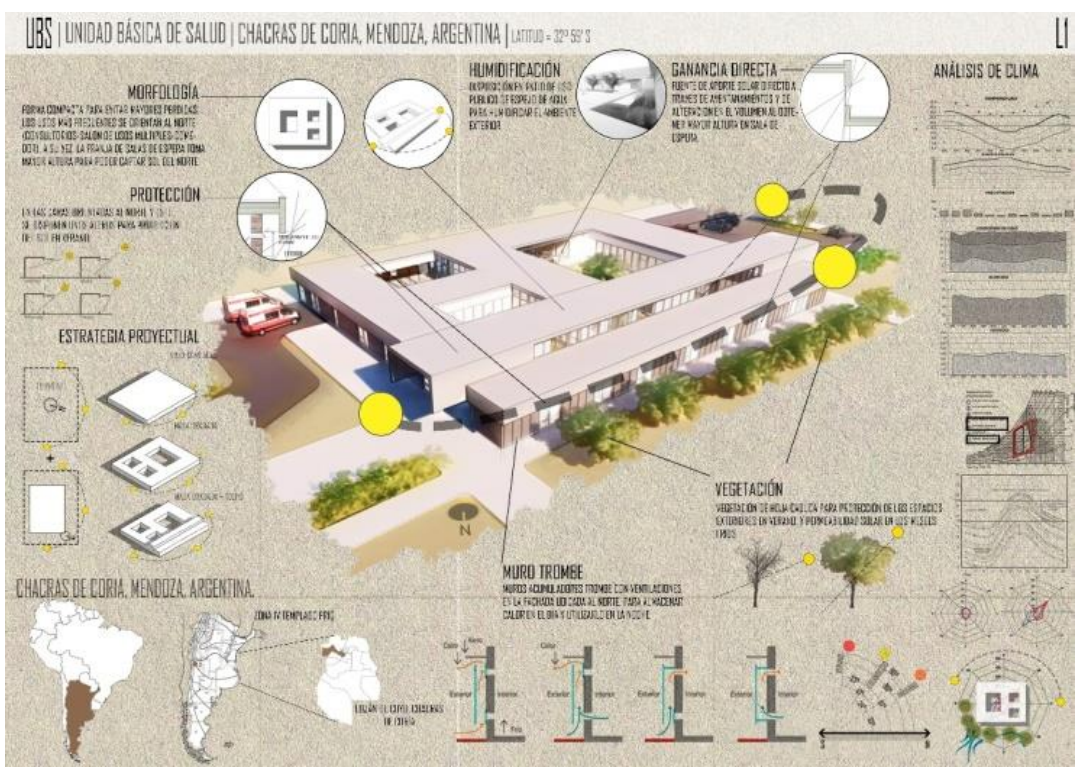

Fonte: autor 


\section{REFERENCIAS}

EVANS J. M. Y de SCHILLER S., “DiseñoBioambiental y Arquitectura Solar”, Ediciones Previas, EUDEBA, Buenos Aires, 1996.

GONZALO, GUILLERMO “Manual de Arquitectura Bioclimática”, Tucumán, Argentina, 2003

OLGYAY, V. "Arquitectura y Clima, Manual de diseño bioclimático para arquitectos y urbanistas”, GG Barcelona, 1998.

PEARCE E. A. \& SMITH C. G., "The world weather guide”, Hutchinson, London, 1990.

SERVICIO METEOROLÓGICO NACIONAL, Estadísticas meteorológicas 1981-1990, Serie B № 37, n. 425-429. Buenos Aires, 1992.

\section{NOTAS}

1- Projeto desenvolvido para a matéria "Introducción al Diseño Bioclimático" da FADU-UBA, a cargo de Mag.Arq. Claudio Delbene e assessorado por Ana Maria Compagnoni. Foiapresentado no Concurso Estudantil Ibero-Americano de Arquitetura Bioclimática da XI Bienal José Miguel Aroztegui e está publicado em http://bienalaroztegui.arq.ufsc.br/

2- welcomeargentina.com disponível em http:/www.welcomeargentina.com/mendoza/chacras-coria-gastronomia.html

3- mendozatravel.com disponível em http://www.mendozatravel.com/chacras/galeriadefotos.html.

NOTA DO EDITOR (*) O conteúdo do artigo e as imagens nele publicadas são de responsabilidade do(s) autor(es). 